\title{
CORRESPONDENCE
}

\section{Slots in the Wings of Birds}

The Editor, The Journal of the Royal Aeronautical Sochety.

Dear Sir,-Dr. Lachmann in the article, entitled "Slots in the Wings of Birds," which appeared in the April number of the JOURNAL OF THE ROYAL AEroNAUtical SocteTy, gives some very interesting and instructive comparisons of the loadings of birds and aeroplanes, and at the same time makes some comments on the subject of slots, which seem to call for an answer.

Regarding the wrist slot, he writes, "I am firmly convinced that this is quite a useless appendage. . . . I cannot believe that it has any aerodynamic importance, because it is much too small and far too much inboard to be of stabilising assistance." He bases this conviction on figures which he gives for the size of the wrist slot, namely, " hardly 5-8 per cent. of the semi-span."

It would appear either that some mistake was made in arriving at these figures from the data provided in the original paper, entitled " Safety Devices in the Wings of Birds," or that they were obtained independently by some different form of measurement. According to the table of flight characteristics in the paper, the wrist slots of birds vary in length between ro-26 per cent. of the semi-span. Actually in the table, the slots are given as fractions of the length of the wing. This was considered to be a fairer method because that part of the bird's body which must be included in the semi-span does not seem to have much to do with the matter. Considered in this way, the slots come out as II-30 per cent. (slot factors $0.1 \mathrm{I}-0.3^{\circ}$ ); in other words, the smallest is more than twice as big as Dr. Lachmann says, and the largest more than four times as big.

The photograph of the wing of a willow grouse, a continental variety of our Scottish ptarmigan, shows that in this bird, at any rate, the wrist slot is of no mean size; the wing is r in. long and the slot 2.7in. It is hard to believe that a slot of this size is useless, especially when the relatively small slots of more easily observed species, such as the rook and seagulls, can clearly be seen operating when the birds are gliding at slow speed. Many photographs bear out this observation.

With regard to position in the wing, no claim has been made by the writer that the wrist slot may be of stabilising assistance. It is thought that it acts for the most part as a lift slot, in which case the centre of the span of the wing would surely be a good position for it.

The case for the utility of the slot is strengthened by the fact that young birds, on leaving the nest, apparently have fully developed bastard wings, while their main wings are still considerably smaller than in the adult bird. So far, fledgling birds of only three species have been measured, but they all show this significant discrepancy in the size of the wrist slot compared with the full grown 
birds. As can be seen in the table of flight characteristics, a fledgling swallow has a wrist slot which is 17 per cent. of the length of the wing, and the adult bird only I 3 per cent. The figure for a fledgling song-thrush on its first day out of the nest was 30 per cent.; for the full-grown bird 17 per cent. It is pleasant to think that these young hopefuls, who have to set out on their first solo flights without any dual instruction, perhaps have their chance of success measurably improved by the provision of man's size safety devices in their untried and under-sized wings.

This leads to Dr. Lachmann's firm belief that the slots of birds do not act as safety devices in the same way as those of aeroplanes, and that the senses of birds are so marvellously developed that they have no need of safety devices.

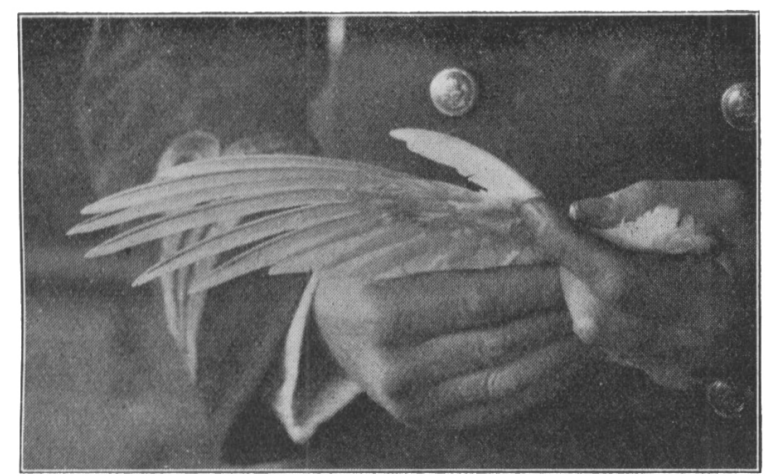

Under-surface of the right wing of a willow grouse with the slot forming bastard wing raised in order to show its proportions.

This particular comment perhaps does not call for an answer, for it probably hinges upon different interpretations of the words " safety device," but it does bring out a rather interesting point in connection with safety in flight. It is common knowledge nowadays that many good pilots, whose senses must have become somewhat attuned to their calling, persist, in spite of warnings from the Air Ministry, in using the slots in their machines more for reducing the minimum speed at which they can fly with safety than for providing a margin of error. It is the same with the comparatively small winged birds which cannot, on account of their manner of living, afford to have long lightly loaded wings of the seagull-swallow type; they unconsciously rely upon their slots to permit them to fly at lower speeds, and therefore with greater safety, than they could manage with unslotted wings. Their marvellous senses would be of no avail without the necessary gear for carrying out their messages. Considered in this way, surely the slots in birds' wings act in the same manner as those of aeroplanes.

Dr. Lachmann asks, "Why, if slots in birds' wings are safety devices, do gulls not have them?" This question calls for another, "Why, if slots in aeroplanes are a safety device, do some machines not have them?" The answer to both questions is that there are certain types of aeroplanes and birds which can be provided, on account of the purpose for which they were designed, or their manner of living, with wings of such a shape and size that even at low 
speeds they will do all that is required of them without the use of angles of incidence great enough to warrant the provision of slots.

The advantages which slots give to birds in gliding flight are only a secondary, though highly interesting consideration, and Dr. Lachmann's conviction that they are of first importance in flapping flight is heartily agreed with.

Yours faithfully,

R. R. Graham,

Lieut.-Commander, R.N. 